\title{
Statistical analysis and dimensioning of a wind farm energy storage system
}

\author{
BARTOSZ WAŚKOWICZ \\ Institute of Electrical Engineering, University of Zielona Góra \\ Szafrana 2, 65-980 Zielona Góra, Poland \\ e-mail:b.waskowicz@iee.uz.zgora.pl
}

(Received: 23.09.2016, revised: 03.11.2016)

\begin{abstract}
The growth in renewable power generation and more strict local regulations regarding power quality indices will make it necessary to use energy storage systems with renewable power plants in the near future. The capacity of storage systems can be determined using different methods most of which can be divided into either deterministic or stochastic. Deterministic methods are often complicated with numerous parameters and complex models for long term prediction often incorporating meteorological data. Stochastic methods use statistics for ESS (Energy Storage System) sizing, which is somewhat intuitive for dealing with the random element of wind speed variation. The proposed method in this paper performs stabilization of output power at one minute intervals to reduce the negative influence of the wind farm on the power grid in order to meet local regulations. This paper shows the process of sizing the ESS for two selected wind farms, based on their levels of variation in generated power and also, for each, how the negative influences on the power grid in the form of voltage variation and a shortterm flicker factor are decreased.
\end{abstract}

Key words: energy storage, power quality, renewable energy, wind power

\section{Introduction}

With the ever-increasing demand of energy consumption and numerous environmental concerns it is of increasing significance to modernize the energy grid [1]. Modern day energy grids are more efficient, produce more energy, use more distributed energy generating units and put less emphasis on fossil fuels. This approach means that maintaining high power quality indices becomes harder due to a much higher number of generating stations which experience greater output variation than traditional power plants [1]. However, it is possible to make renewable energy generating stations more stable by adding energy storage.

Depending on local law and legal regulations it is possible to achieve required parameters by using appropriate energy storage to stabilize the power output of such generating stations as wind farms. According to the Polish power transmission regulations [2,3], a wind farm 
should not generate output with sudden dips or spikes exceeding $1.5 \%$ of the reference power level and should have a short-term flicker factor below 0.35 .

Many methods are being used for storage sizing but there is no generally accepted framework. The two most commonly used methods are the deterministic approach and the stochastic approach. More uncommon methods include genetic algorithms [4], artificial neural networks [5], application of low-pass filter methodology [6], and using inventory models [7].

\subsection{Storage role and type}

Energy storage can be used in conjunction with a wind farm for several reasons. One of which is to minimize the influence of the wind farm on the power grid by either reducing the Pst, or making it possible to meet the day-ahead forecast. However one of most important reasons is to meet the short-circuit criterion in certain areas where grid parameters do not allow for connecting additional wind generation stations. Also incorporation of a storage system makes it possible to use wind farms on the power balance market. The economic aspect of storage systems is complicated and largely unregulated. It seems intuitive that DSOs should create new possibilities for incorporating new renewable energy plants. Thus they should be interested in implementing energy storage as a simpler, faster and cheaper way to open the grids to new distributed energy sources. On the other hand, in some cases (when technical issues have not been resolved and the whole project is doubtful) investors in renewables should also be interested in financing energy storage systems. To make a 24 hour forecast it is impossible to do so based on statistical data alone [8]. Therefore it is necessary to use historical meteorological data. Even though this is proven to work by many case studies it requires energy storage with huge capacity because of the power balancing over many hours. Additionally, uncertainty of the forecast requires even larger storage capacity to account for the possible deviation from the forecast. Typical capacities of such storages are around few MWh $[1,6,9]$, depending on wind characteristics and wind farm rated power, and they are very costly. Typically used energy storage technologies for long forecasts are pumped hydroelectric storage, sodium-sulfur batteries, among others. Using an ESS to reduce destabilizing influences on the power grid does not require the use of historical data nor meteorological data. This role requires storage capacities two orders of magnitude smaller than the balancing storage, as shown in this paper. While the energy capacity required is relatively small it is still necessary to supply a large power output for smoothing brief power fluctuations. Different storage technologies are being used for these two roles because of the aforementioned reasons. Possible storage technologies here are supercapacitors, flywheel energy storage and superconducting magnetic energy storage.

\subsection{Method types}

Deterministic methods use mathematical models to analyze the system and calculate the capacity of the storage needed. Such methods are often used for long term forecasts ( $24 \mathrm{~h}$ or over) and they often include historical meteorological data and sometimes take into account multisite correlation. Such models are very complicated and require the determination of values of numerous parameters. This, along with the uncertainty of meteorological and histo- 
rical data, makes such methods difficult to implement and determine the accuracy of such methods. Also, forecast tools are not widespread [9] and forecast error greatly impacts on the necessary storage capacity $[8,9]$. Although deterministic methods are able to make $24 \mathrm{~h}$ forecasts and wind farms have been proven to function using forecasting in many case studies [10] they require very large capacities of ESS. Also due to unpredictability of weather forecasting it is impossible to determine the confidence level of the system in question.

The stochastic approach may appear more appropriate to deal with such an unpredictable element as wind speed. It is best suited for short-term prediction and balancing. It is impossible to make a $24 \mathrm{~h}$ forecast based on statistical data alone. There are cases where stochastic methods were applied but they had to be combined with weather data for making a $24 \mathrm{~h}$ forecast $[1,9]$. Analyzing the required storage capacity using statistical methods is convenient because it does not require the determining of numerous parameters and it is always possible to get an accurate confidence level using a histogram of power generation variation which is useful especially when dealing with the customer. Statistics alone can be useful for determining storage capacity for short or very short forecast applications.

As already stated, there is no established method or framework of optimal storage sizing. Often, authors in their papers do not reveal all technical details of their methods, diminishing the transparency of their research. Existing methods are quite difficult to adequately compare in terms of efficiency, and therefore do not show a clear superiority of one over the others. There are a few reasons for this, one of which is that there are different types of methods and while different deterministic methods can be analytically compared, it cannot be done between deterministic and stochastic or more exotic approaches. But the main reason is different wind data and wind farm characteristics. There is no benchmark data that could be fed to tested methods to calculate a fair result. This may be caused by the fact that detailed ( $1 \mathrm{~s}$ intervals) wind data are very hard to come by and are often tied to a non-disclosure agreement.

\subsection{Proposed method}

The purpose of the proposed method is the reduction of negative influence from wind farm dynamics on the power grid using as small an energy storage capacity as possible. To achieve this the method optimizes the storage size by setting constant levels of output power at $1 \mathrm{~min}$ intervals. This power level of $i$-th cycle is determined by calculating the average power value $P_{\mathrm{wf}}$ in the previous $1 \mathrm{~min}$ interval and adding a correction $A_{i-1}$, which is determined on the basis of the current storage charge level according to the formula:

$$
P_{\mathrm{ref}, i}=\frac{1}{n} \sum_{j=1}^{n} P_{\mathrm{wf}, i-1}\left(t_{j}\right)+A_{i-1}\left(t_{0}\right),
$$

where: $P_{\text {ref, } i}$ is the power level set in $i$-th interval, $P_{\mathrm{wf}}$ is the wind farm power, $A_{i}(t)$ correction parameter determined by current storage discharge level.

An advantage of this method is its simplicity, robustness and the fact that it does not require the determination of numerous parameters to function nor any historical data or meteorological data. It can be deployed virtually anywhere and can reduce unwanted power fluctuations and thus the short-term flicker factor $\left(P_{S T}\right)$. 


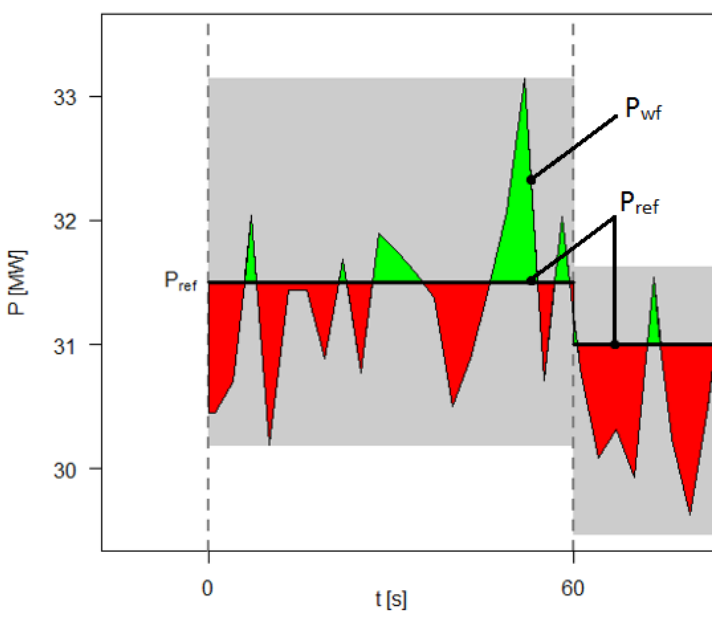

Fig. 1. Fluctuations of active power $\left(P_{\mathrm{wf}}\right)$ compared to constant power levels $\left(P_{\text {ref }}\right)$ at 1 min intervals

Fig. 1 illustrates the method and its influence on the output power. The method only allows one rise or fall of power level every minute. Also the magnitude of this fall or rise will virtually always be a lot lower than the magnitude of regular wind farm power fluctuations, thus significantly smoothing power output.

Further sections of this paper include statistical analysis, its purpose, different steps taken, simulation assumptions and the conditions the simulation was conducted in, experimental results in different conditions illustrated with active power fluctuations, histograms of active power variation, a histogram of storage charge levels, detailed tables, summary tables and the impact of the wind farm connected to high-voltage grid.

\section{Input data}

The data used in this article consist of the result of experimental 10 min measurements of power outputs of two wind farms:

1) Location A Wind Farm $(12 \times 3.3 \mathrm{MW}=39.6 \mathrm{MW})$ - over the period of 31 months.

2) Location B Wind Farm $(12 \times 2.5 \mathrm{MW}+2 \times 3.3 \mathrm{MW}=36.6 \mathrm{MW})-$ over 37 months.

It is important to emphasize that the abovementioned data do not allow for in-depth analysis of output power level dynamics, though they do allow, for active power output estimation over long periods of time (months/years). Knowledge of short-term (one minute and below) power fluctuations is necessary in power prediction and regulation.

Fig. 2a illustrates the averaged values of active power obtained for different wind speeds presented with histograms. Based on these power levels, the power curve was estimated. It is worth noting that the power curve determined on the basis of the measurements differs (is greater) than the power curve declared by the manufacturer. Further study is based on the power curve obtained from the analysis. 


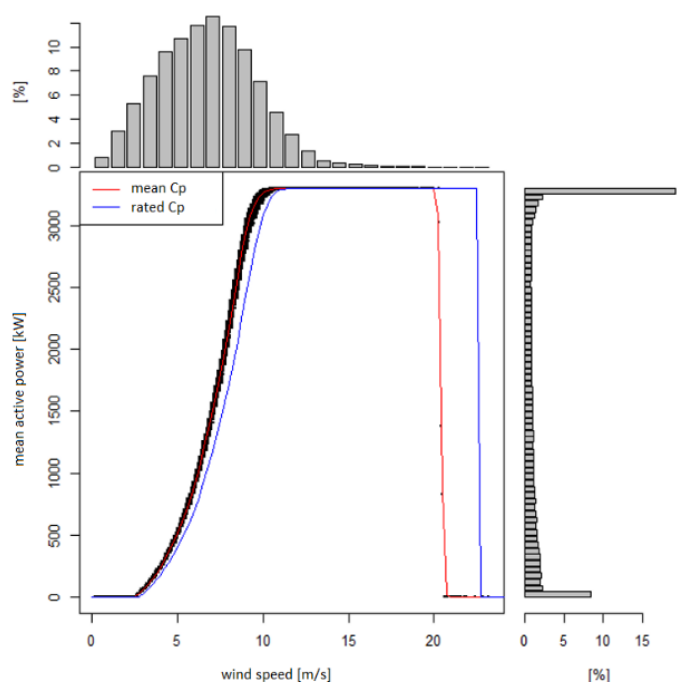

a)

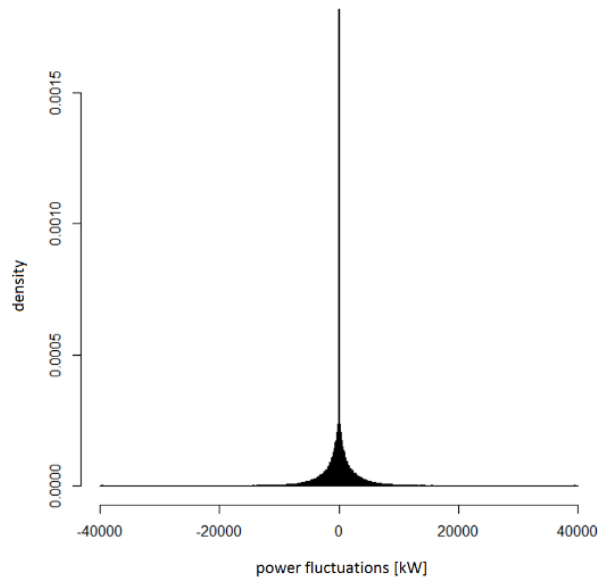

b)

Fig. 2. a) Power curves and histograms of wind speed and active power generated by one of the wind farm turbines in Location A; b) Distribution of power changes generated by the wind farm

Having solid information of short-term fluctuations is most important for simulating power distribution and the state of charge for $1 \mathrm{~min}$ intervals. Information on $10 \mathrm{~min}$ power changes will be the starting point for further assumptions. The graph above (Fig. 2b) shows the distribution of total wind farm power.

The distribution of average power increases over 10 min periods is symmetrical with respect to 0 , which means that in every subsequent interval an increase or decrease in output power is equally likely. As shown in Table 1, the changes are within the range of $-39.6 \mathrm{MW}$ to $39.6 \mathrm{MW}$. Also around $99 \%$ of changes are in the range of $-11 \mathrm{MW}$ to $11 \mathrm{MW}$. Analysis of $99 \%$ of cases is especially important, keeping in mind the Polish power distribution regulations. These regulations require the power quality indices to be above a certain level $99 \%$ of the time in a one-week period [2]. Table 1 shows how the selection of a storage unit for $99 \%$ of cases of power changes between intervals $(0.5 \%$ to $99.5 \%)$ allows for a significant reduction of storage capacity.

Table 1. Ranges of power changes generated by Location A wind farm

\begin{tabular}{c|c|c|c|c|c|c}
\hline \multicolumn{7}{c}{ Quantile of power change [kW/10 min] } \\
\hline $\min$ & $0.5 \%$ & $25 \%$ & $50 \%$ & $75 \%$ & $99.5 \%$ & $\max$ \\
\hline-39600 & -11313.09 & -875.37 & 0.0 & 845.67 & 11857.93 & 39600 \\
\hline
\end{tabular}

Identical analysis was conducted for Location B wind farm receiving very similar results. 


\section{Statistical analysis}

The purpose of the simulation is to determine the required storage capacity in different conditions and compare results. Storage capacities will be determined according to the proposed 1 min interval method, which sets every subsequent power level according to Eq. 1.

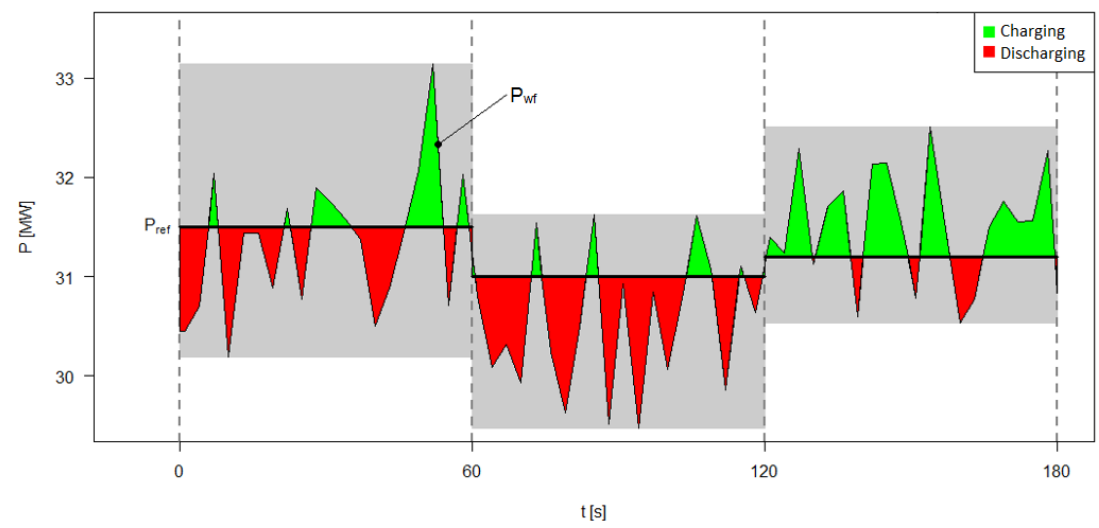

Fig. 3. Power fluctuations of the wind farm without magazine $\left(P_{\mathrm{wf}}\right)$ and with energy storage $\left(P_{\text {ref }}\right)$

This model allows for control of the level of charge of the storage by setting prediction of active power in subsequent one-minute intervals for large active power fluctuations with no apparent trend shown in Fig. 3. The obtained power prediction values along with the amount of power required to compensate the power fluctuations constitute the basis for determining the energy storage capacity. For the sake of analysis it is assumed that the base level of charge storage is $50 \%$, which enables charging or discharging of the successive instants of time. The capacity obtained from simulation has to be treated as usable capacity. If the battery type does not allow for total discharge it is necessary to oversize the energy storage.

Fig. 3 illustrates the changes of wind farm power output with and without storage in the form of a graph. Power output with storage is identical to predicted power values $\left(P_{\text {ref }}\right)$. The maximum fluctuation range is used to analyze the influence of the wind farm on the power quality indices at the point of connection as well as the required storage capacity.

\section{Simulation assumptions}

Simulation only concerns power changes corresponding to ranges between starting speed and rated rotational speed of the rotor. In other cases with speed exceeding the maximum, the power plant experiences no fluctuation.

In order for the short-term simulations to be meaningful at all there has to be data from fluctuations of said time interval. Therefore, short-term fluctuation magnitude has been simulated and injected into the received data on the basis of experimental study results published 
in [11], maintaining consistency of variability indices with provided experimental data. The power curve used in the analysis was estimated using the supplied simulation data.

Supplied data were enriched with simulated short-term data $(1 \mathrm{~s}$ interval) in a few scenarios to illustrate the effectiveness of the sizing method in favorable and unfavorable conditions and to determine the required storage capacity. Therefore simulations were carried out for power following trend lengths of $1 \mathrm{~min}$ and $10 \mathrm{~min}$. Both simulations of trend lengths were carried out in two trend slopes variants of $0.9 \mathrm{MW} / 10 \mathrm{~min}$ to $11 \mathrm{MW} / 10 \mathrm{~min}$ and the range from 0 to $0.9 \mathrm{MW} / 10 \mathrm{~min}$.

With reference to the above, a list of executed simulations is given below. All four simulations were conducted for both considered wind farms:

Simulation 1 - Trend slope is a random value from the range of 0.9 to $11 \mathrm{MW} / 10 \mathrm{~min}$. Direction of trend is changed randomly every $10 \mathrm{~min}$.

Simulation 2 - Trend slope is a random value from the range of 0.9 to $11 \mathrm{MW} / 10 \mathrm{~min}$. Direction of trend is changed randomly every minute.

Simulation 3 - Trend slope is a random value from the range of 0 to $0.9 \mathrm{MW} / 10 \mathrm{~min}$. Direction of trend is changed randomly every $10 \mathrm{~min}$.

Simulation 4 - Trend slope is a random value from the range of 0 to $0.9 \mathrm{MW} / 10 \mathrm{~min}$. Direction of trend is changed randomly every minute.

\section{Simulation results}

Simulation 1 was chosen as an example to illustrate the methodology, with partial results obtained. An identical procedure was performed for all scenarios and both wind farms. Summary results of all variants of conditions are presented in Table 3 . The table illustrates the influence of the trend slope and trend length on required the storage capacity $\left(C_{\min }\right)$.
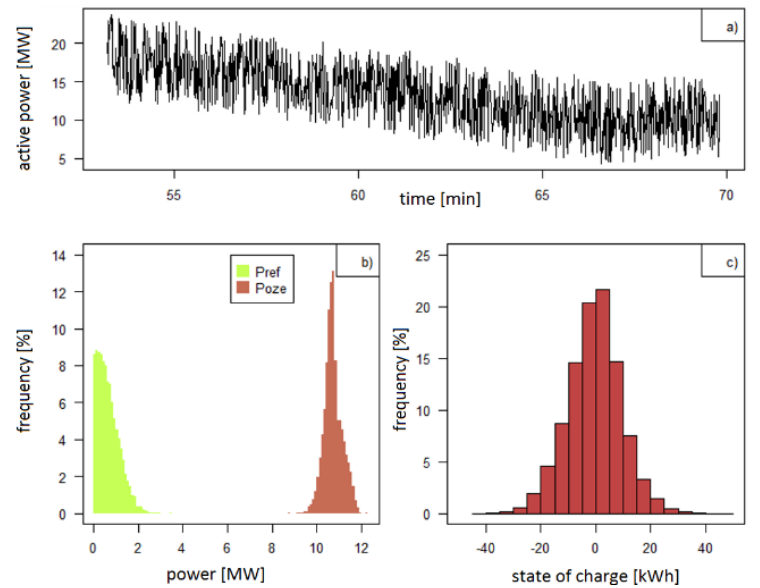

Fig. 4. a) Active power fluctuations over 15 min period; b) histogram of reference and active power level changes; c) histogram of storage charge levels 
Table 2. Estimation of the minimum ESS capacity $\left(C_{\min }\right)$ based on $99 \%$ reference power $\left(P_{\text {ref }}\right)$ changes

\begin{tabular}{cc|c|c|c|c|c}
\hline \multicolumn{2}{l|}{ Reference power $[\mathbf{k W}]$} & \multicolumn{5}{|c}{ Energy storage [kWh] } \\
\hline $\max$ & $99 \%$ range & $\max$ & $\min$ & $99 \%$ range & $C_{\min }$ \\
\hline 3420.7 & 2079.2 & -44.1 & 46.4 & -26.4 & 25.8 & $\mathbf{5 2 . 8}$ \\
\hline
\end{tabular}

Table 3. Consolidated list of estimates of the minimum usable energy storage capacity $\left(C_{\min }\right)$ based on $99 \%$ power change reference $\left(P_{\text {ref }}\right)$ for all the analyzed cases

\begin{tabular}{l|c|c|c|c|c|c|c}
\hline & \multicolumn{6}{c}{ Reference power [kW] } & \multicolumn{5}{c}{ Energy storage [kWh] } \\
\hline & $\max$ & $99 \%$ & $\max$ & $\min$ & $99 \%$ range & $C_{\min }$ \\
\hline Location A Wind Farm \\
\hline Sim. 1. & $\mathbf{3 4 2 0 . 7}$ & 2079.2 & -44.1 & 46.4 & -26.4 & 25.8 & 52.8 \\
\hline Sim. 2. & $\mathbf{3 4 0 4 . 7}$ & 1980.5 & -43.0 & 49.5 & -25.1 & 25.1 & 50.1 \\
\hline Sim. 3. & $\mathbf{2 2 7 0 . 6}$ & 1538.3 & -35.2 & 36.4 & -19.8 & 19.6 & 39.7 \\
\hline Sim. 4. & $\mathbf{2 4 0 9 . 5}$ & 1532.3 & -35.0 & 36.5 & -19.7 & 19.8 & 39.6 \\
\hline Location B Wind Farm & \multicolumn{7}{|c}{} \\
\hline Sim. 1. & $\mathbf{3 2 5 2 . 8}$ & 1697.0 & -36.5 & 39.6 & -23.0 & 21.2 & 45.9 \\
\hline Sim. 2. & 2526.3 & 1704.0 & -36.0 & 36.4 & -21.1 & 21.2 & 42.4 \\
\hline Sim. 3. & 1969.7 & 1137.6 & -27.8 & 29.4 & -15.0 & 14.9 & 30.1 \\
\hline Sim. 4. & 1730.1 & 1148.6 & -28.5 & 27.9 & -14.7 & 15.0 & 30.1 \\
\hline
\end{tabular}

As shown in Table 3 the proposed method is not influenced greatly by the length of the trend, performing similarly in favorable and unfavorable conditions. However the magnitude of power fluctuations in the said trends understandably influences the calculated capacity.

The robustness of this method is a result of its simplicity. It can be widely used however it is best suited to environments where there are very short or no clear trends. Also as a result of its simplicity it is easy and cheap to implement.

\section{Energy storage technologies}

Having determined the exact storage parameter requirements, it is now possible to determine the real characteristics of the ESS by choosing the type of ESS technology. Some of the best suited storage systems are considered below with all their characteristics taken into account in respect of both technical and economic aspects. Both wind farms have different power and energy requirements and thus different ideal $\mathrm{C}$ parameter. Location A storage requirements would be fulfilled with a technology having charge and discharge currents of $39.4^{\circ} \mathrm{C}$ as showed below (2).

$$
C_{R A T E}=\frac{P}{E}=\frac{2079.2[\mathrm{~kW}]}{52.8[\mathrm{kWh}]} \cong 39.4\left[\frac{1}{\mathrm{~h}}\right],
$$

where: $C_{R A T E}$ is the $\mathrm{C}$ factor, $P$ is the storage power, $E$ is the storage capacity. 
Location B storage requirements on the other hand would be satisfied with a technology with charge and discharge currents of $37.1 \mathrm{C}$ as showed below (3).

$$
C_{\text {RATE }}=\frac{P}{E}=\frac{1704.0[\mathrm{~kW}]}{45.9[\mathrm{kWh}]} \cong 37.1\left[\frac{1}{\mathrm{~h}}\right] .
$$

Li-Ion - Lithium Ion batteries are one of the most common and widely used battery types. They exhibit high specific energy of $200 \mathrm{Wh} / \mathrm{kg}$ and $400 \mathrm{Wh} / 1$ [12], relatively high power for an electrochemical battery of $300 \mathrm{~W} / \mathrm{kg}$, and have a life of around 6000 cycles and discharge current of up to $0.5^{\circ} \mathrm{C}$. The dimensioning process is problematic because it requires massive oversizing of the storage system to meet the power requirements.

Location A - Because the Li-Ion technology's characteristics are very different powerwise $\left(0.5^{\circ} \mathrm{C}\right)$ than the characteristics for this specific storage implementation $\left(39.4^{\circ} \mathrm{C}\right)$ it is required to oversize the Li-Ion storage to get the necessary power, which is shown below.

$$
E=\frac{P}{C_{R A T E}^{\mathrm{Li}-\mathrm{Ion}}}=\frac{2079.2[\mathrm{~kW}]}{0.5\left[\frac{1}{\mathrm{~h}}\right]} \cong 4158.5[\mathrm{kWh}] .
$$

The calculated capacity is almost 80 times the required capacity thus the theoretically cheapest technology $(900 \$ / \mathrm{kWh})$ no longer has the lowest cost.

$$
I M_{\mathrm{Li}-\mathrm{Ion}}=E \cdot M_{\mathrm{Li}-\mathrm{Ion}}=4158.4[\mathrm{kWh}] \cdot 900\left[\frac{\$}{\mathrm{kWh}}\right]=3742560[\$],
$$

where: $I M_{\mathrm{Li}-\mathrm{Ion}}$ is the total investment cost of considered Lithium Ion storage, $M_{L \mathrm{~L}-\mathrm{I} o n}$ is the cost of Lithium Ion batteries per kWh, $E$ is the storage capacity [kWh].

Location B - Similarly in the case of location B power is the limiting factor again. The wind farm has different parameters and all calculations were made in the same way.

$$
\begin{gathered}
E=\frac{P}{C_{R A T E}^{\mathrm{Li}-\text { Ion }}}=\frac{1704[\mathrm{~kW}]}{0.5\left[\frac{1}{\mathrm{~h}}\right]} \cong 3408[\mathrm{kWh}], \\
I M_{\mathrm{Li}-\mathrm{Ion}}=E \cdot M_{\mathrm{Li}-\mathrm{Ion}}=3408.4[\mathrm{kWh}] \cdot 900\left[\frac{\$}{\mathrm{kWh}}\right]=3067200[\$] .
\end{gathered}
$$

The smaller wind farm (location B) naturally requires smaller and less expensive energy storage. Additionally, the 2000 cycle life of a Li-Ion storage system can pose a problem, however the vast capacity can also be used for other uses than fluctuation suppression.

EDLC - Electric double-layer capacitors are based on different phenomena than electrochemical batteries. They accumulate electrical charge rather than storing energy in chemical form, therefore they have much higher rated power, charge and discharge currents and power ramp. Their estimated lifetime often exceeds 1000000 cycles or 20 years [13]. This type of storage is mainly used in short cycle, power intensive uses [14]. EDLC supercapacitors have a high power density of over $10000 \mathrm{~W} / \mathrm{kg}$ and low energy density or around $5 \mathrm{Wh} / \mathrm{kg}$ [14-16]. 
Location A - Since EDLC supercapacitors have a $\mathrm{C}$ factor of over $100^{\circ} \mathrm{C}$ and power is no longer the limiting factor there is no need to oversize the storage system. The estimated price per $\mathrm{kWh}$ is $44500 \$ / \mathrm{kWh}$. An additional important point is the 0 to $100 \%$ voltage operating range. It becomes necessary to limit the operating range to enable correct operation of converters. For the purpose of calculations the voltage range is reduced to 25 to $100 \%$.

The reduced voltage range has been taken into account by increasing the storage capacity and multiplied by EDLC's cost per $\mathrm{kWh}$ to determine the investment cost in the equation:

$$
I M_{\mathrm{EDLC}}=\frac{E}{D O D} \cdot M_{\mathrm{EDLC}}=\frac{52.8[\mathrm{kWh}]}{0.75} \cdot 44500\left[\frac{\$}{\mathrm{kWh}}\right]=3132800[\$] .
$$

Location B - The same calculations were carried out for Location B.

$$
I M_{\mathrm{EDLC}}=\frac{E}{D O D} \cdot M_{\mathrm{EDLC}}=\frac{45.9[\mathrm{kWh}]}{0.75} \cdot 44500\left[\frac{\$}{\mathrm{kWh}}\right]=2723400[\$] .
$$

Even taking the reduced depth of charge into account the most expensive technology per $\mathrm{kWh}$ becomes more economically justified because no significant oversizing is required. Storage based on supercapacitors will have a very long life, require little to no maintenance and pose no environmental threat.

LIC - Lithium Ion Capacitors are supercapacitors that combine high power with increased capacity from $5 \mathrm{Wh} / \mathrm{kg}$ to about $20 \mathrm{Wh} / \mathrm{kg}$. LIC supercapacitors have different voltage ranges than EDLC of around $40 \%$ of rated voltage, which guarantees full utilization of stored energy. LIC supercapacitors have low inner resistance, high charge and discharge currents (30C).

Location A - Although lithium supercapacitors have high currents up to $30 \mathrm{C}$ the storage will still have to be oversized but a lot less than the Li-Ion storage variation.

$$
C_{R A T E}^{\mathrm{LIC}}=\frac{P}{E}=\frac{2079.2[\mathrm{~kW}]}{30\left[\frac{1}{\mathrm{~h}}\right]} \cong 69.3[\mathrm{kWh}] .
$$

LIC are slightly less expensive than regular EDLC supercapacitors costing around $40000 \$ / \mathrm{kWh}$ resulting in lower investment costs.

$$
I M_{\mathrm{LIC}}=E \cdot M_{\mathrm{LIC}}=69.3[\mathrm{kWh}] \cdot 40000\left[\frac{\$}{\mathrm{kWh}}\right]=2771167[\$] .
$$

Location B - The same calculations were carried out for Location B.

$$
\begin{gathered}
C_{R A T E}^{\mathrm{LIC}}=\frac{P}{E}=\frac{1704.2[\mathrm{~kW}]}{30\left[\frac{1}{\mathrm{~h}}\right]} \cong 56.8[\mathrm{kWh}], \\
I M_{\mathrm{LIC}}=E \cdot M_{\mathrm{LIC}}=56.8[\mathrm{kWh}] \cdot 40000\left[\frac{\$}{\mathrm{kWh}}\right]=2272266.7[\$] .
\end{gathered}
$$

Although they are not ideal and still require a slightly oversized capacity, lithium supercapacitors seem to have the closest $\mathrm{C}$ parameter to the calculated storage system. 
Cost Summary - Costs of each individual storage type for the two considered wind farms are shown in the table below.

Table 4. Summary table of initial cost of considered storage technologies

\begin{tabular}{l|c|c|c}
\hline & \multicolumn{3}{|c}{ Investment Cost [\$] } \\
\hline Site & Li-Ion & EDLC & LIC \\
\hline Location A & 3742560 & 3132800 & 2772267 \\
\hline Location B & 3067200 & 2723400 & 2272267 \\
\hline
\end{tabular}

Storage based on LIC supercapacitors is the best suited parameter-wise and also the best from an economic standpoint, both in initial investment and maintenance costs.

\section{Impact analysis}

According to local regulations $[2,3]$ sudden power changes $\left(\Delta P_{\mathrm{wf}}\right)$ cannot exceed $1.5 \%$ for 100 dips or spikes an hour, and short-term flicker factor $\left(P_{S T}\right)$ cannot be greater than 0.35 . Both the above-mentioned indices were calculated taking all required transformer and line characteristics into account [17] and are illustrated below.

Table 5. Summary of power quality indices improvement

\begin{tabular}{l|c|c|c|c}
\hline \multirow{2}{*}{} & \multicolumn{2}{|c|}{$\Delta P_{\mathrm{wf}}[\%]$} & \multicolumn{2}{c}{$P_{S T}$} \\
\cline { 2 - 5 } & No ESS & With ESS & No ESS & With ESS \\
\hline Allowed & \multicolumn{2}{|c}{1.5} & \multicolumn{2}{c}{0.35} \\
\hline Location A & 1.78 & 0.50 & 0.64 & 0.18 \\
\hline Location B & 1.38 & 0.47 & 0.5 & 0.17 \\
\hline
\end{tabular}

As shown in Table 5, the incorporation of ESS in two cases of separate wind farms enables them to operate in the grid, whereas both wind farms would be unable to participate in energy exchange in the power system without energy storage.

\section{Conclusions}

The situation on the energy market today makes it necessary to take into account penetration of the power grid by renewable energy generation which has a large variation in output power. Thus, the aim of this article has been to present an efficient means of dimensioning of energy storage using a specially developed control algorithm, which has been demonstrated in the case of two selected wind farms.

A storage control method has been developed and proposed in this paper as a way to reduce the required storage capacity of energy storage systems used to decrease wind farm 
power fluctuations. The method relies on the setting of one-minute intervals at a constant output level for the wind farm, using the storage system to absorb all deviations from the reference level. The power level of each subsequent interval is calculated taking the mean power value of the previous interval and the level of charge in the ESS as shown in Eq. 1. Such a system causes the output power to be constant, with only a single rise or fall of power between the intervals. In this way, the method reduces power variation and the negative influence of the wind farm on the power system. Depending on local regulations different wind farms may be required to employ an ESS to be allowed to operate within the power system and a control strategy is an effective way to reduce the required storage capacity and thus the cost of the ESS. The simulation study shown the robustness of the developed method and that it can substantially decrease storage capacity even taking into account the most unfavorable conditions of a short or non-distinguishable trend in output power, establishing the variation amplitude as the only impactful factor for this method.

The Lithium Ion Capacitor was chosen as the best suited technology for the designed storage system. It has the right proportion of power and energy, and while it is expensive it is still a better and less problematic option than EDLC and Lithium Ion batteries. EDLC are more expensive and difficult to fully discharge while Li-Ion batteries require massive oversizing and have a shorter estimated life.

The capacities calculated using the developed method are quite small compared to other methods found in the literature. The result is $52.8 \mathrm{kWh}$ for a $39.6 \mathrm{MW}$ wind farm which makes $1.3 \mathrm{kWh}$ per MW and $45.9 \mathrm{kWh}$ for a $36.6 \mathrm{MW}$ which makes $1.25 \mathrm{kWh}$ per MW. The $P_{S T}$ factor has been successfully reduced from 0.5 to 0.17 , which is a $68 \%$ reduction. For instance in [6] a storage capacity of $5 \mathrm{kWh}$ per MW reduces the standard deviation of generated power by $10 \%$ and a storage capacity of $25 \mathrm{kWh}$ per MW reduces the standard deviation by $50 \%$ in most cases.

Further studies will consider further development by using a linear, exponential or a polynomial function instead of a constant value. Other more specialized control methods may use more sophisticated prediction algorithms. A different challenge is to adjust the methods to work with hybrid storage systems, which although they need to be developed to suit each individual deployment, look like being the most cost efficient way to satisfy every ESS need.

\section{Acknowledgement}

The research was supported by the National Centre for Research and Development (Narodowe Centrum Badań i Rozwoju) within the project No. PBS3/A4/13/2015 entitled "Superconducting magnetic energy storage with a power electronic interface for the electric power systems" (original title: "Nadprzewodzący magazyn energii $\mathrm{z}$ interfejsem energoelektronicznym do zastosowań $\mathrm{w}$ sieciach dystrybucyjnych"), 01.07.2015-30.06.2018.

\section{References}

[1] Shokrzadeh S., Jozani M. J., Molinski T., A statistical algorithm for predicting the energy storage capacity for baseload wind power generation in the future electric grids, Energy (2015). 
[2] Power grid codes of transmission network. Terms of use, operation and planning of network development. Version 2.1 (in Polish), The consolidated text of the Charter of renovation CK / 1/2012 approved by the President of URE No. DPK-4320-2 (16) / 2010 - 2013 / LK (2013).

[3] PN-EN 50160: 2002 Voltage characteristics of electricity supplied by public distribution networks

[4] Luo Y., Shi L., Tu G., Optimal sizing and control strategy of isolated grid with wind power and energy storage system, Energy Conversion and Management, vol. 80, pp. 407-415 (2014).

[5] Zhang Y., Tang X., Qi Z., Liu Z., The Ragone plots guided sizing of hybrid storage system for taming the wind power, Electrical Power and Energy Systems, vol. 65, pp. 246-253 (2015).

[6] Paatero J.V., Lund P.D., Effect of Energy Storage on Variations in Wind Power, Wind Energy, vol. 8, no. 4, pp. 421-441 (2005).

[7] Schneidera M., Bielb K., Pfallera S., Schaedea H., Glockb C.H., Optimal sizing of electrical energy storage systems using inventory models, Energy Procedia, vol. 73, pp. 48-58 (2015).

[8] Jaworsky C., Turitsyn K., Backhaus S., The Effect of Forecasting Accuracy on the Sizing of Energy Storage, ASME 2014 Dynamic Systems and Control Conference (2014).

[9] Haessig P., Multon B., Ahmed H.B., Lascaud S., Bondon P., Energy storage sizing for wind power: impact of the autocorrelation of day-ahead forecast errors, HAL (2013).

[10] Korpaas M., Holen A.T., Hildrum R., Operation and sizing of energy storage for wind power plants in a market system, Electrical Power \& Energy Systems, vol. 25, issue 8, pp. 599-606 (2003).

[11] Lubośny Z., Wind farms in the power system, monograph, WNT Publishing House, Warsaw (2013).

[12] William E.J., Gupta V., Huff M., Linda O., Govar J., A Comparative Study of Lithium Poly-Carbon Monoflouride (Li/CFx) and Lithium Iron Phosphate (LiFePO4) Battery Chemistries for State of Charge Indicator Design, Contract M67854-08-C 6530 (2009).

[13] Gualous H., Alcicek G., Diab Y., Hammar A., Venet P., Adams K., Marumo C., Lithium Ion capacitor characterization and modelling, ESSCAP' (2008).

[14] Abbey C., Joos G., Supercapacitor energy storage for wind energy applications, IEEE Transactions on Industry Applications, vol. 43, no. 3, pp. $769-776$ (2007).

[15] Jayalakshmi M., Balasubramanian K., Simple capacitors to supercapacitors-an overview, Int. J. Electrochem. Sci., col. 3, no. 11, pp. 1196-1217 (2008).

[16] Díaz-González F., Sumper A., Gomis-Bellmunt O., Villafáfila-Robles R., A review of energy storage technologies for wind power applications, Renewable and Sustainable Energy Reviews, vol. 16, no. 4, pp. 2154-2171 (2012). 